\title{
Responses of Crayfish Muscle Preparations to Nerve Stimulation with Various Patterns of Impulse Sequence. Effects of Intermittent, Intercalated and Adaptational Types of Impulse Sequence
}

\author{
TSutomu Wakabayashi and Toshiko Kuroda \\ Department of Physiology, Tokyo Medical College, Shinjuku-ku, \\ Tokyo 160
}

\begin{abstract}
WaAabayashI, T. and Kuroda, T. Responses of Crayfish Muscle Preparations to Nerve Stimulation with Varions Patterns of Impulse Sequence. Effects of Intermiltent, Intercalated and Adaptational Types of Impulse Sequence. Tohoku J. exp. Med., 1977, 121 (3), 207-218—The present study was carried ont with an attempt to see what effects would be produced by various patterns of impulse trains other than pulses of a definite frequency in nerve-muscle systems of the crayfish. Single axons of nerves of the opener, the slow closer and the fast closer of the crayfish claw were stimulated and the tension development of muscles were recorded. The impulse trains tested are as follows: (i) the intermittent stimulation; e.g. paired (doublet) and triplet stimuli, (ii) the intercalated stimulation. during stimulation by constant-frequency pulses and (iii) the adaptational type of stimulation, i.e. a train of pulses of which interval gradually increases as seen in the process of the adaptation in the sensory nerve. Results obtained are as follows. Intermittent doublet stimuli produced a greater tension than the monotonous stimulation of the same average frequency. Repetitive triplet or quadruplet stimuli caused further increments in the tension development. Intercalation of a stimulus during usual monotonous stimulation induced a catchlike effect on the tension. Intercalated triplet stimuli provoked a stronger catch action. With the adaptational type of stimulation, an initial rapid tension development occurred with a least latency and this was followed by a maintained tension. There are certain temporal configurations of stimuli which produce a greater tension or a more physiologically meaningful time course of tension development. This suggests the significance of nervous coding._— temporal pattern of stimuli; adaptational stimulation; intermittent stimulation
\end{abstract}

It has been known that in sensory nerve the intensity of input stimulus is transmitted in terms of the impulse frequency (frequeney modulation). There may be other types of communication in nerve impulses than the frequency modulation, e.g., a temporal configuration of impulses.

In this study, the exploration was made on the effect of nerve stimulation by different types of impulse sequence in crayfish nerve-muscle preparations. The impulse sequences in physiological nerve activity have been investigated since Bronk and Ferguson (1934) (Bronk and Stella 1934; Hagiwara 1949, 1950, 1954; Wakabayashi and Hagiwara 1949; Pringle and Wilson 1952; Fessard and Tauc 1958;

Received for publication, March 31, 1976. 
Tokizane and Shimazu 1964; Ikeda and Wiersma 1964; Wilson and Davis 1965; Moore et al. 1966; Atwood and Wiersma 1967; Gillary and Kennedy 1969; French et al. 1972; Snith 1974a, b). Effects of artificial stimulations with impulse trains of various patterns were investigated by several investigators. An intermittent stimulation was studied by Wiersma and Adams (1950), Ripley and Wiersma (1953), Douglas et al. (1956), Segundo et al. (1963, 1966). Intercalated pulses given during a basic regular train of impulses were investigated by Balashko et al. (1931), Wilson and Larimer (1968), Burke et al. (1970) and Wakabayashi et al. (1976a, b).

A new type of stimulation, "adaptational" stimulation, was introduced in the present study in addition to the intermittent and intercalated stimulation. "Adaptational" means "adaptation-like" patterns of train which resembles those seen in the process of the adaptation in sensory nerve and does not mean the induction of the adaptation effect. A preliminary study of impulse sequence with progressively increasing intervals was reported by Wakabayashi and Saito (1959), subsequently by Wakabayashi $(1961,1965)$ and Wakabayashi and Kuroda (1976).

\section{Materials and Methods}

The nerve-muscle preparations were obtained from the claw opener, the slow closer and the fast closer of the crayfish, Procambarus clarkii, by the technique after Wiersma (1941). The limbs were firmly clamped on a wooden support so that only the dactylopodite could move freely. 'The meropodites containing the nerve were placed in Harreveld's physiological solution and the nerve bundles were exposed by removing one side of the shell. The end of the dissected motor axon was sucked about $3-4 \mathrm{~mm}$ into the tip of the suck electrode which had a stimulating $\mathrm{Ag}$-AgCl electrode and was filled with Harreveld solution. An indifferent $\mathrm{Ag}-\mathrm{AgCl}$ electrode was immersed in the bath. The trunk which contained single axon of the opener was easily detected. As axons of both the slow and the fast closers were contained in a single nerve trunk, the trunk was divided into two bundles in trial. In a favourable case, stimulation of one of separated bundles caused the slow response while the stimulation of the other gave the fast response. When such a trial failed, further dissection was made. Only the bundles in which the slow or the fast closer were identified were used in the experiment. By using the suck electrode, spread of a stimulating current could be minimized. Almost isometric tension was recorded by connecting the end of the movable tip of the claw to a strain gauge transducer. A small tension was applied to the opener by loading $5 \mathrm{~g}$ load, and to the closer by $10 \mathrm{~g}$ load. The tension development was registered with an ink writing recorder at the paper speed of $1 \mathrm{~mm} / \mathrm{sec}$. The experiments were carried out from July to next March. In summer, room temperature was kept under $21^{\circ} \mathrm{C}$. The temperature of the bathing solution ranged from $16^{\circ}$ to $20^{\circ} \mathrm{C}$. The intermittent doublet, triplet and quadruplet stimuli as well as the constant frequency stimulation were applied by the use of an electronic stimulator (Type MSE-3R, Nihon Koden Kogyo Co.) For the intercalation of single or triplet stimuli during a train of basic stimulation pulses, a special device was connected to the stimulator to interpose extra pulses with a delay after a definite number of pulses of the basic stimulation. This delay was precisely measured by simultaneous photographic recording of oscilloscopic display.

To gain the adaptation-like train of pulses, a photoelectronic device was used (Fig. 1). Light from an appropriate lamp passing through a narrow slit was collected by a concave mirror to focus on a photoelectric cell, which transduced light energy to electric energy. When a signal is given to the device, a condenser installed in it begins to be charged to a critical voltage, at which the condenser discharges automatically. Thereafter, it begins to be charged again. This device produces a train of pulses while the illumination continues. 


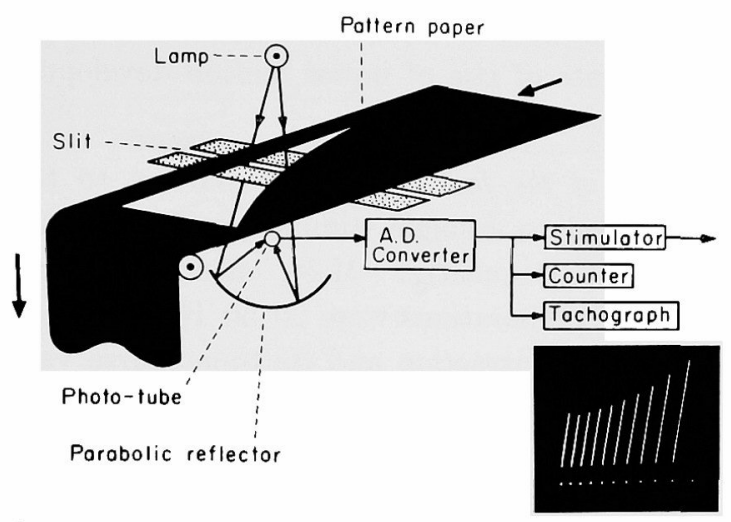

Fig. 1. Outline of the device for "adaptational" stimulation. Explanation see the text. Inset (right below) is an example of a tachogram in which white vertical lines denote the intervals (arbitrary unit between pulses), and white plots indicate the moments of each stimulation

\begin{abstract}
A reduction of the quantity of light prolongs the time necessary to reach the critical voltage, therefore reduces the frequency. The quantity of light was changed in the following way. A sheet of black paper which had an opening of a special form was slided in front of the slit. Thus, various patterns of pulse train by changing the quantity of light could be obtained. The intervals of applied pulses were recorded by the use of a tachograph beside each myogram. Sheets of black paper with different pattern were provided beforehand. The number of pulses to be applied was preset with a counter device before experiments. Applied pulses had the duration of $0.5 \mathrm{msec}$ and an intensity slightly above the threshold.
\end{abstract}

\title{
Results
}

As the functional state of the preparations could not be maintained satisfactorily steady, the stimulation was usually given by interposing a certain period of rest by about 3-5 min. The difference between responses to the test and the control stimuli was regarded as satisfactorily significant when it was large enough as compared with spontaneous fluctuations. As reported by Wiersma and Adams (1950), there were inherent differences among various preparations in regard to the response. Many preparations were pattern-sensitive but some others pattern-insensitive. In the latter, the response depended on only the number of stimuli. The opener and the slow closer of the claw were mostly the former type. The fresh preparations of the fast closer were the latter, but some of them became pattern-sensitive by aging.

\section{Effect of intermittent stimulation}

Effect of tetanization on the opener and the slow closer. At first the effect of usual monotonous stimulation was investigated in the axons. The results were as follows. (i) The opener was inactive to a single stimulus and responded with a very small contraction to a short train of $100 \mathrm{~Hz}$. (ii) The optimal frequency for eliciting contraction was $200 \mathrm{~Hz}$ in the case of brief stimulation, but it somewhat 
decreased when the total number of stimuli was increased. The same was observed in the slow closer. The rate of rise of initial tension development was high when the frequency of stimulation was high.

Effect of tetanization of the fast closer. In contrast to the slow closer, the fast closer muscle responded to a single stimulus, but the contraction was rapidly fatigued when stimulated frequently. Most effective frequencies to produce strong contraction in fresh preparations were $20-50 \mathrm{~Hz}$ in the case of not so brief stimulation. The height of contraction and its time course varied little when the frequency of stimuli was changed. The tension development was strongest in the fast closer.

Effect of intermittent doublet stimulation - the spacing effect (Ripley and Wiersma 1953). An example of results of experiments carried out in the opener was demonstrated in Fig. 2, where the spacing effect of the doublet stimulation was tested. The slow and the fast closers were also investigated under the same conditions that the total number of stimuli was fixed at 50 and the mean frequency at $33.3 \mathrm{~Hz}$. The spacing interval was optimal at $4-5 \mathrm{msec}$. The spacing effect was expressed by $H_{s} / H_{e}$, where $H_{s}$ is the height of contraction in response to

$a$

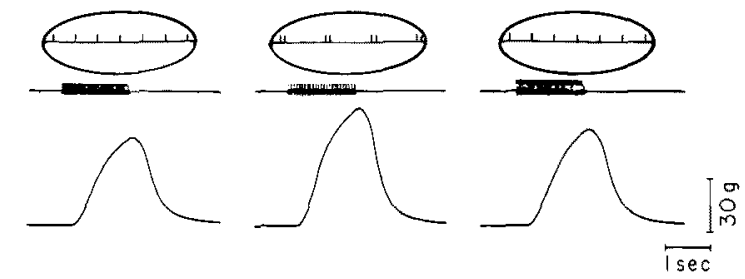

b

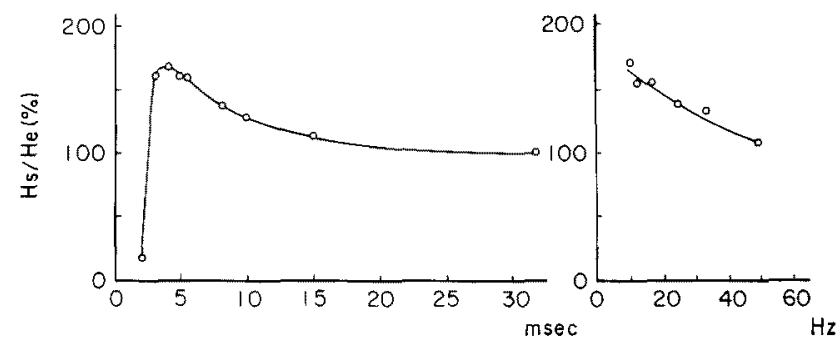

Fig. 2. Effect of donblet stimulation on the motor axon of the claw opener of Procambarus clarkii. a) Mean frequency was $33.3 \mathrm{~Hz}$ in all the records. The temporal patterns of stimuli are illustrated in ellipses. The records of stimuli are shown in the second row, and the contraction curves in the third row. Isometric contractions by the monotonous stimulation were recorded before (left) and after (right) the test (middle) with the doublet stimulation. The interval in the doublet (spacing interval) of the latter was 5 msec. Total number of stimuli was 50 in each. b) Left: Relationship between the spacing effects (ordinate) and the spacing intervals (abscissa). Total number of stimuli was 200. Right: Relationship between the spacing effect and the mean frequency. Total number of stimuli was 60 ; spacing interval 5 msec. March 19. 
a

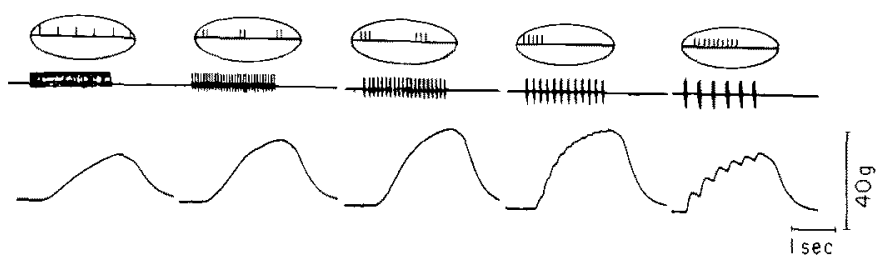

b

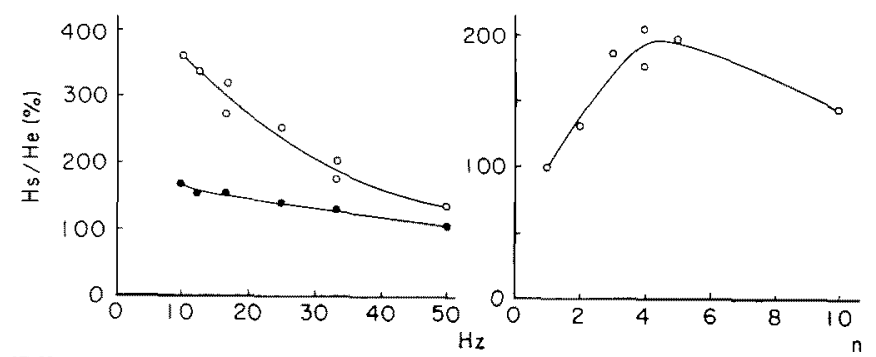

Fig. 3. a) Effects of doublet, triplet and more grouping types of stimulation in the claw opener. Mean frequency $33.3 \mathrm{~Hz}$. Figures are illustrated in the similar way to that in Fig. 2. Number of stimuli was 60 .

b) Left: Relationship between the spacing effect and the mean frequency. Total number of stimuli was 60 . Solid circles, doublet stimuli; open circles, quadruplet stimuli. Right: Relationship between the spacing effect and the number of pulses in a group $(n)$. Mean frequency was $33.3 \mathrm{~Hz}$. Number of stimuli was 60 . Another preparation. Temps. $19^{\circ} \mathrm{C}$, March 19.

the test stimuli and $H_{e}$ the height of contraction by the control stimulation (monotonous train of the same mean frequency). In Fig. 2b, with the spacing interval of $5 \mathrm{msec}$, the spacing effect became larger when the mean frequency was lowered.

The number of stimuli in a group. Fig. 3 shows the effects of doublet-, triplet-, quadruplet-pulse stimuli. The uppermost tracings in the pannel-a show the patterns of stimuli. The maximal tension development was seen when grouping number (n) was 5 (see lower tracings). The pannel-b shows that quadruplet stimuli (open circles) had a larger spacing effect than doublet stimuli (solid circles), and that the lower the mean frequency, the larger the spacing effect. The right pannel shows the effect of the grouping number. The maximal effect was seen at 4 .

Slow closer preparation. Fig. 4 shows an example of the responses to the intermittent doublet, quadruplet and sextuplet stimulations. The upper pannel-a shows the maximal spacing effect which occurred by the sextuplet stimulation where the response attained to about $200 \%$. In the lower-b left, the optimal mean frequency was found to be about $20 \mathrm{~Hz}$ in the case of the quadruplet stimuli (open circles). The right pannel in Fig. 4-b shows the effect of $n$. The effect increased with increase in $n$. But the effect was limited by the decrease of summation which 
a

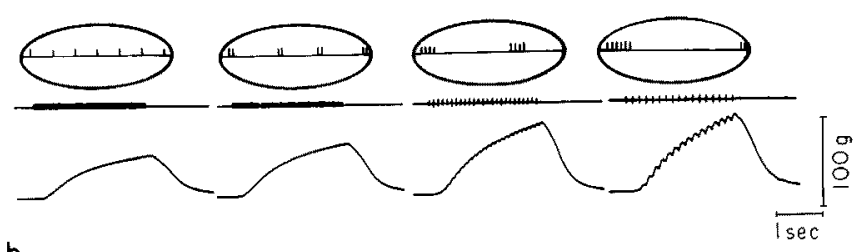

b

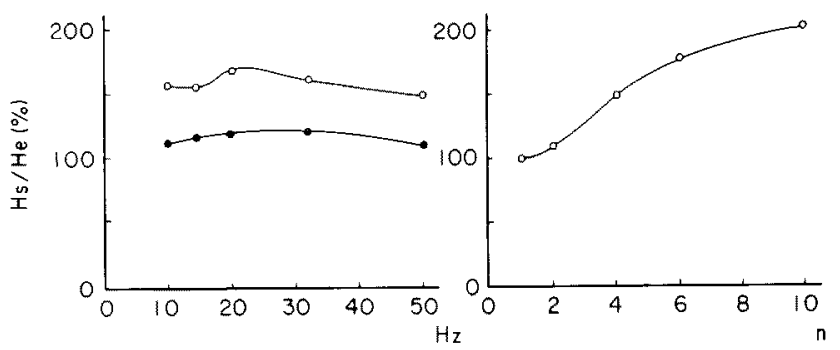

Fig. 4. Effect of the doublet quadruplet and six stimuli in a group on isometric contraction of the slow closer of the elaw. Diagrams are arranged in the same way as in Fig. 3 . a) Maximal contraction occurred at six pulses in a group. Mean frequency $50 \mathrm{~Hz}$; number of stimuli 100. b) Left: The relationship between the spacing effect (ordinate) and mean frequency (abscissa). The spacing effect was maximal at about $20 \mathrm{~Hz}$. Spacing interval $5 \mathrm{msec}$; number of stimuli 100 . Solid circles, doublet; open circles, quadruplet stimuli. Right: The relationship between the spacing effect and the number of stimuli in a group $(\mathrm{n})$. Total number of stimuli: 100 . Temps. $20^{\circ} \mathrm{C}$, Nov. 25.
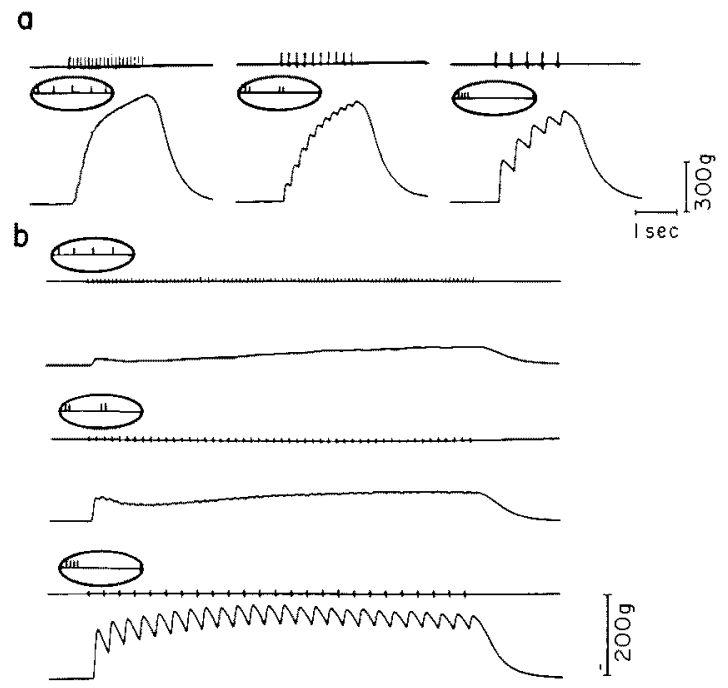

Fig. 5. a) Effects of the doublet and quadruplet stimuli in the fast closer (fresh nervemuscle preparation). Illustrated similarly to Fig. 4a. Negative spacing effect. Mean frequency $10 \mathrm{~Hz}$; total number 20 . Temps. $19^{\circ} \mathrm{C}$, March 20.

b) Examples of responses in the aged fast closer. Tension development was enhanced with quadruplet stimuli. Positive spacing effect. Mean frequency $10 \mathrm{~Hz}$; total number of stimuli 100 . Temps. $19^{\circ} \mathrm{C}$, August 23 . 
TABLE 1. Spacing effect in the claw muscles

\begin{tabular}{|c|c|c|c|c|c|}
\hline Muscle & $\begin{array}{l}\text { Number of } \\
\text { stimuli in } \\
\text { a group }\end{array}$ & $\begin{array}{l}\text { Spacing } \\
\text { interval } \\
\text { (msec) }\end{array}$ & $\begin{array}{c}\text { Mean } \\
\text { frequency } \\
(\mathrm{Hz})\end{array}$ & $\begin{array}{l}\text { Total } \\
\text { number of } \\
\text { stimuli }\end{array}$ & $\begin{array}{c}\text { Spacing } \\
\text { effect } \\
(\%)\end{array}$ \\
\hline \multirow[t]{16}{*}{ Opner } & $3^{*}$ & 5 & 50 & 120 & 185 \\
\hline & $4^{*}$ & 5 & 30 & 120 & 580 \\
\hline & 6 & 5 & 10 & 36 & 152 \\
\hline & 4 & 5 & 10 & 120 & 104 \\
\hline & $4^{*}$ or $5^{*}$ & 5 & 16.7 & 60 & 322 \\
\hline & $4^{*}$ or $5^{*}$ & 5 & 33.3 & 60 & 206 \\
\hline & 2 & $3^{*}$ or $4^{*}$ & 33.3 & 200 & 167 \\
\hline & 2 & 3 & 33.3 & 50 & 175 \\
\hline & 2 & 5 & 33.3 & 50 & 223 \\
\hline & 2 & 5 & 33.3 & 200 & 155 \\
\hline & 2 & 5 & 10 & 60 & 170 \\
\hline & 2 & 5 & 50 & $30^{*}$ & 200 \\
\hline & 2 & 5 & 33.3 & 10 & 161 \\
\hline & 3 & 5 & 33.3 & 120 & 333 \\
\hline & 4 & 5 & 10 & 60 & 360 \\
\hline & 2 & 5 & 10 & 60 & 170 \\
\hline \multirow{8}{*}{$\begin{array}{l}\text { Slow } \\
\text { closer }\end{array}$} & 2 & $5^{*}$ & 40 & 100 & 140 \\
\hline & 2 & 5 & 20 & 100 & 125 \\
\hline & 4 & 5 & $20^{*}$ & 100 & 177 \\
\hline & 2 & 5 & $20^{*}$ & 100 & 127 \\
\hline & 6 & 5 & 33.3 & 100 & 190 \\
\hline & 4 & 5 & 20 & 100 & 168 \\
\hline & 2 & 5 & 33.3 & 100 & 120 \\
\hline & 10 & 5 & 50 & 100 & 210 \\
\hline Fast & 2 & 10 & 10 & 20 & 95 \\
\hline closer & $\overline{2}$ & 5 & 20 & 100 & 135 \\
\hline
\end{tabular}

Asterisk denotes the optimal condition in the respective row; optimal number of stimuli in a group, optimal spacing interval, optimal mean frequency or optimal total number of stimuli. These were determined in the respective row where the other parameters were fixed as described.

results from the increase of the interval between each group.

Fast closer preparation. The fast closer responded to a single shock. The preparations often showed a negative spacing effect as shown in Fig. 5. However, in somewhat aged preparations, the paired stimulation showed a positive spacing effect as shown in (b) and the effect was enhanced by a quadruplet stimulation (the lowest row). The spacing effect, the spacing interval, the mean frequency and number of stimuli in experiments on the opener, the slow closer and the fast closer are summarized in Table 1.

\section{Effect of intercalated stimulation.}

Catch action is a kind of hysteresis phenomenon, which has previously been observed by Balashko et al. (1931) and Wilson and Larimer (1968). In this study a triplet stimulation was intercalated at different moments during a background stimulation of $10 \mathrm{~Hz}$. Catch actions in the slow and the fast closers are shown in 
a

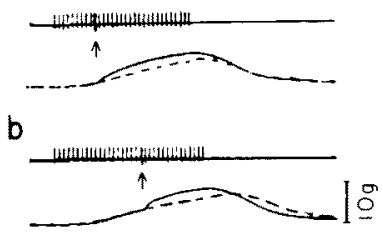

d

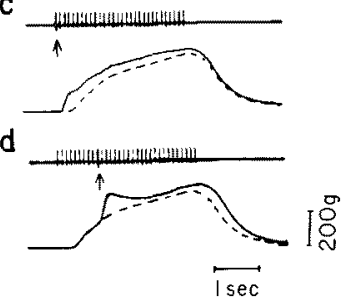

Fig. 6. The effect of intercalation of a triplet stimulus (spacing interval: $9 \mathrm{msec}$ ). $a, b$ : the slow closer. Background stimulation $10 \mathrm{~Hz}$. Intercalated stimulus was given after 10 th stimulus in a and 20 th in $\mathrm{b}$, with the delay of $10 \mathrm{msec} . c, d$ : the fast closer (aged preparation). Background stimulation $10 \mathrm{~Hz}$. Intercalated stimulus was given after lst stimulus in $c$ and 10 th in $d$ with the delay of 10 msec. Temps. $19^{\circ} \mathrm{C}$, March 20.

a

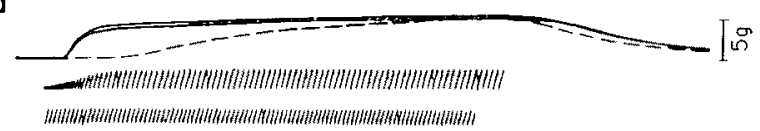

b

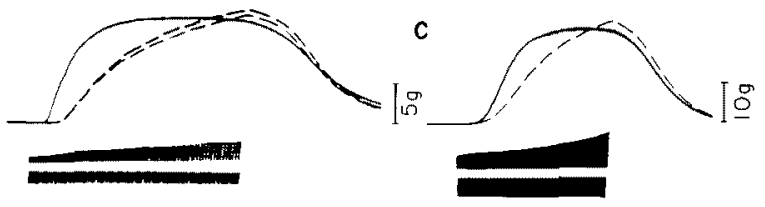

d

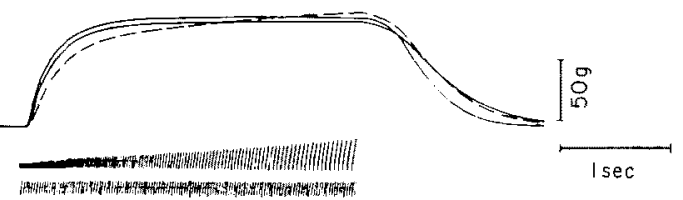

Fig. 7. Effect of "adaptational" stimulation in the claw muscle. Solid lines in each set of records: responses to "adpatational" stimulation, broken lines to control monotonous stimuli of the same mean frequency. The tachograms of stimulus intervals were shown below the tension curves. a) The opener. "Adaptational" stimulation with the initial interval of $10 \mathrm{msec}$ to the final interval of $50 \mathrm{msec}$ was tested before and after control. The interval of the monotonous stimuli was $38.8 \mathrm{msec}$. The number of stimuli was always $100.22 .3^{\circ} \mathrm{C}$, Sept. 18. b) The opener. Monotonous stimulation was given before and after the adaptational one. The interval of the adaptational stimuli varied from 10 to $30 \mathrm{msec}$, monotonous stimulus interval, $18.5 \mathrm{msec}$; the number of stimuli were $100.22 .4^{\circ} \mathrm{C}$, Sept. 18 . c) The slow eloser. The intervals of the adaptational stimuli varied from 10 to $20 \mathrm{msec}$, the interval of monotonous stimuli $13.2 \mathrm{msec}$, the number of stimuli, $100.22 .1^{\circ} \mathrm{C}$, Oct. 16 . d) The fast closer. The sequence of stimulation was the same as in a). The adaptational interval varied from 10 to $40 \mathrm{msec}$; the interval of monotonous pulses $23.4 \mathrm{msec}$, the number of stimuli 130. $17.6^{\circ} \mathrm{C}$, Nov. 2 .

Fig. 6. The increase in tension development by the intercalated stimulation is demonstrated by superposing the tracings on those obtained by the basic stimulation only. The triplet shock was given after the first pulse of the basic stimulation 
in Fig. 6. c, after the 10th in Fig. 6a and d, and after 20th pulse in Fig. 6b. The effect was largest in $d$.

\section{Effects of adaptational stimulation.}

When an appropriate pattern of adaptational stimulation, the frequency of which was initially high and becoming gradually lower, was used, a rapid development of tension which was followed by a plateau was obtained. Fig. 7 shows the tracings of tension development recorded from the opener ( $a$ and $b$ ), from the slow closer (c) and from the fast closer (d). To compare the tension curves obtained with an appropriate adaptational stimulation to those obtained with the monotonous stimulation of the same mean frequency, the curves are superposed. The pattern of train of stimuli (a tachographic record) is shown in each case below the myograms.

It is seen that a more rapid development followed by maintenance of tension is obtained with the adaptational stimulation. Effects were most remarkable in a, $\mathrm{b}$ and $\mathrm{c}$ recorded from the opener and the slow closer.

\section{Discussion}

Ripley and Wiersma (1953) reported that the contraction of the crayfish muscle was strengthened when the nerve was stimulated by intermittent pulses of doublet or triplet type. Gillary and Kennedy (1969) showed the similar phenomenon in crayfish abdominal muscle. In the present study, the number of grouped pulses was extended to sextuplet. It was found that there was an optimal number of pulses of grouping in the intermittent stimulation.

In certain crustacean muscles, so-called Blashko effect was observed. A single impulse in an excitatory motor axon to the crayfish claw closer muscle produced only a small contraction, while a low-frequency train of impulses gave rise to a slowly developing but much a larger tension. Moreover a single extra impulse intercalated during this train produced a marked excess contraction which was maintained beyond the duration of normal twitch. If a brief high-frequency train of impulses is added during the low-frequency background stimulation, a further increase in tension will be obtained and the increased tension will be maintained long even after the extra stimulus is withdrawn. It was confirmed in the present study that multiple stimuli interposed in a regular repetitive stimuli produced a remarkable holding effect.

Wiersma (1951) investigated the effect of spacing of four shocks in time on the opener contraction of the hermit crab. Segundo et al. (1963) found in isolated ganglia of Aplysia that the difference of interspike interval distribution and sequence of three shocks at a given mean frequency applied to a connecting nerve trunk brought about a different pattern of the output (EPSPs or spikes). They suggested the possibility of the significant coding in the biological system. Segundo et al. (1966) also carried out experiments with random shocks and studied the probability of triggering a spike generation in a postsynaptic cell by processing the temporal sequence in train of presynaptic spikes and moreover by simulating the 
neuron with a digital computer. Wilson and Larimer (1968) studied the hysteresis in the insect muscle contraction by stimulating the excitatory axon with a sinusoidally modulated impulse train. The pattern of impulse train they adopted resembled in part that of "adaptational" stimulation which was examined in the present work. Quick development and subsequent maintenance of the muscular tension could be evoked by this specific type of stimulation. The observed responses may be advantageous for movements in emergency.

All doublet stimulations did not always produce large spacing effect as shown in Table 1. Effective responses were obtained with optimum patterns by choosing suitable parameters. Similarly in the adaptational stimulation, it was of course necessary to select a suitable pattern by trials for producing an effect above described.

It may be of some physiological interest to consider the connection of the following two phenomena described below. One is the adaptational pattern found in the afferent nerve such as the report of Hensel and Zotterman (1951) in the nerve fiber from the frog tongue, and of Hartline and Graham (1932) in the Limulus optic fiber. Similar pattern was found by Fourtes (1959) in the spike potential series from an impaled eccentric cell of Limulus ommatitdium. The other is the fact demonstrated in this report that the adaptationally patterned stimulation given to the efferent nerve can evoke a fairly plateau like continuation of muscle contraction. These may suggest some possible connection of coding and decoding in the nervous system. The adaptational pattern of impulses may produce adaptational modulation in the physiological communication.

\section{Acknowledgment}

We are grateful to Dr. Kawamura, Chief of Neurophysiology Laboratory, MitsubishiKasei Institute of Life Sciences for reading this manuscript, and to Professor Y. Yamashita, Dept. of Electrical Engineering of Chuo University and Mr. K. Tateno, Nihon-Koden-Kogyo Co. for their contributions to electrotechnical devices. This work was partly supported by grants from the Ministry of Education.

\section{References}

1) Atwood, H.L. \& Wiersma, C.A.G. (1967) Command interneuron in the crayfish central nervous system. J. exp. Biol., 46, 249-261.

2) Blashko, H., Cattel, M.K. \& Kahn, J.L. (1931) On the nature of the two types of responses in the neuromuscular system of the crustacean claw. J. Physiol., 73, 25-35.

3) Bronk, D.W. \& Ferguson, L.K. (1934) The nervous control of intercostal respiration. Amer. J. Physiol., 110, 700-707.

4) Bronk, D.W. \& Stella, A.G. (1934) The response to steady pressure of single endorgans in the isolated carotid sinus. Amer. J. Physiol., 110, 708-714.

5) Burke, R.E., Rudomin, P. \& Zájac III, F.E. (1970) Catch property in single mammalian motor units. Science, 168, 122-129.

6) Douglas, W.W., Ritchie, J.M. \& Schaumann, W. (1956) A study of the effect of the pattern of electrical stimulation of the aortic nerve on the reflex depressor responses. J. Physiol., 133, 232-242.

7) Fessard, A.\& Tauc, L. (1958) Effects of repetition sur l'amplitude des potentials postsynaptituqes d'un soma neuroniques. J. Physiol. (Paris), 50, 277-281. 
8) Fourtes, M.G.H. (1959) Initiation of impulses in visual cells of Limulus. J. Physiol. 148, 14-28.

9) French, A.S., Holden, A.V. \& Stein, R.B. (1972) The estimation of the frequency response function of a mechanoreceptor. Kybernetik, 11, 15-23.

10) Gillary A. \& Kennedy, D. (1969) Neuromuscular effects of impulse pattern in a crustacean motoneuron. $J$. Neurophysiol., 32, 607-612.

11) Hagiwara, S. (1949) On the fluctuation of interval of the rhythmic excitation. I. The efferent impulse of the human motor unit during the voluntary contraction. (in Japanese with English summary). Bull. Physiograph. Sci. Res. Inst., Tokyo Univ., $3,19-24$.

12) Hagiwara, S. (1950) On the fluctuation of the interval of the rhythmic excitation. II. The efferent impulse from the tension receptor of the skeletal muscle. Preliminary report. (in Japanese with English summary) Bull. Physiograph. Sci. Res. Inst., Tokyo Univ., 4, 28-35.

13) Hagiwara, S. (1954) Analysis of interval fluctuation of the sensory nerve impulses. Jap. .J. Physiol., 4, 234-240.

14) Hartline, H.K. \& Graham, C.H. (1932) Nerve impulses from single receptors in the eye. J. cell. comp. Physiol., 1, 277-95.

15) Hensel, H. \& Zotterman, Y. (1951) Quantative Beziehungen zwischen der Entladung einzelner Kaltfaser und der Temperatur. Acta physiol. scand., 23, 291-317.

16) Ikeda, K. \& Wiersma, C.A.G. (1964) Autogenic rhythmicity in the abdominal ganglion of the crayfish: the control of swimmerlet movements. Comp. Biochem. Physiol., 12, 107-115.

17) Moore, G.P., Perkel, D.H. \& Segundo, J.P. (1966) Statistical analysis and functional interpretation of neuronal spike data. Ann. Rev. Physiol, 28, 493-522.

18) Pringle, J.W.S. \& Wilson, V.J. (1952) The response of a sense organ to a harmonic stimulus. J. exp. Biol., 29, 220-235.

19) Ripley, S.H. \& Wiersma, C.A.G. (1953) The effect of spaced stimulation of excitatory and inhibitory axons of the crayfish. Physiol. comp. ('s-Grav.), 3, 1-17.

20) Segundo, J.P., Stensas, L.J. \& Bullock, T.H. (1963) Sensitivity of neurons in A plysia to temporal pattern of arriving impulses. J. exp. Biol., 40, 643-667.

21) Segundo, J.P., Perkel, D.H. \& Moore. G.P. (1966) Spike probability in neurons: Influence of temporal structure in the train. Kybernetik, 3, 67-82.

22) Smith, D.O. (1974a) Autogenic production of paired impulses by the opener excitator neuron of the crayfish claw. Brain Res., 70, 356-360.

23) Smith, D.O. (1974b) Central nervous control of excitatory and inhibitory neurons of opener muscle of crayfish claw. J. Neurophysiol., 37, 108-118.

24) Tokizane, T. \& Shimazu, H. (1964) Functional Differentiation of Human Skeletal Muscle: Corticalization and Spinalization of Movement. University of Tokyo Press, Tokyo.

25) Wakabayashi, T. (1961) Studies on adaptative repetitive stimulation (A.R.S.). (in Japanese with English summary). Tokyo J. med. Sci., 69, 177-178.

26) Wakabayashi, T. (1965) Studies on the effect of pattern of nervous impulse. Tokyo Ikadaigaku Zasshi (Jap.), 23, 71-76.

27) Wakabayashi, T. \& Hagiwara, S. (1949) Some analysis of excitation of human muscle. No-kenkyu (Jap.) (Brain Research), 5, 43-54.

28) Wakabayashi, T. \& Saito, T. (1959) Adaptative repetitive stimulation. Seitai no Kagaku (Jap.), 10, 22-27.

29) Wakabayashi, T., Satow, Y. \& Osumi, .Y (1976a) Pattern stimulation and action potential of frog's skin. (in Japanese with English summary) J. physiol. Soc. Jap., $37,411-421$.

30) Wakabayashi, T., Satow, Y. \& Osumi, T. (1976b) Pattern stimulation and salivary secretion. (in Japanese with English summary). J. physiol. Soc. Jap., 38, 1-14.

31) Wakabayashi, T. \& Kuroda, T. (1977) Effects of stimulation with impulse trains of various patterns, including adaptational type, on frog's nerve-muscle and spinal reflex 
preparations. Tohoku J. exp. Med., 121, 219-229.

32) Wilson, D.M. \& Davis, W.J. (1965) Nerve impulse pattern and reflex control in the motor system of the crayfish claw. J. exp. Biol., 43, 193-210.

33) Wilson, D.M. \& Larimer, J.L. (1968) The catch property of ordinary muscle. Proc. nat. Acad. Sci. (Wash.), 61, 909-916.

34) Wiersma, C.A.G. (1941) The inhibitory nerve supply of the leg muscles of different decapod crustacenans. J. comp. Neurol., 74, 63-79.

35) Wiersma, C.A.G. (1951) A bifunctional single motor axon system of a crustacean muscle. J. exp. Biol., 28, 12-21.

36) Wiersma, C.A.G. Adams, R.T. (1950) The influence of nervous impulse sequence on the contractions of different crustacean muscles. Physiol. comp. ('s-Grav.), 2, 20-33. 